\title{
AXILLARY NERVE INJURY - A CLINICAL CASE AND REVIEW OF MANAGEMENT STRATEGIES
}

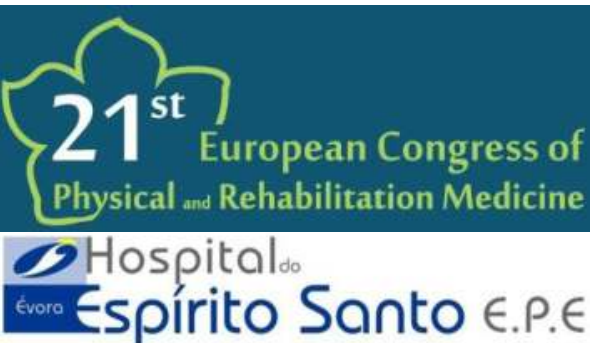

\author{
Rangel Madalena ${ }^{1}$, Claro Sandra ${ }^{1}$, Galo Sergio² \\ 1 Department of Physical and Rehabilitation Medicine, Hospital do Espírito Santo de Évora, Portugal \\ 2 Department of Radiology, Hospital do Espírito Santo de Évora, Portugal
}

Introduction The axillary nerve arises from cervical roots $\mathrm{C5}$ and C6 and it is a terminal branch of the brachial plexus (Figure 1a). In its anatomical course it passes along the anteroinferior portion of the subscapularis muscle before crossing posteriorly the quadrilateral space. It then divides into two major trunks responsible for nervous supply of the deltoid and teres minor muscles. Injury can occur at any anatomical site and can result from closed or penetrating trauma, repetitive microtrauma, traction, compression, neuritis, quadrilateral space syndrome or iatrogenic lesion.

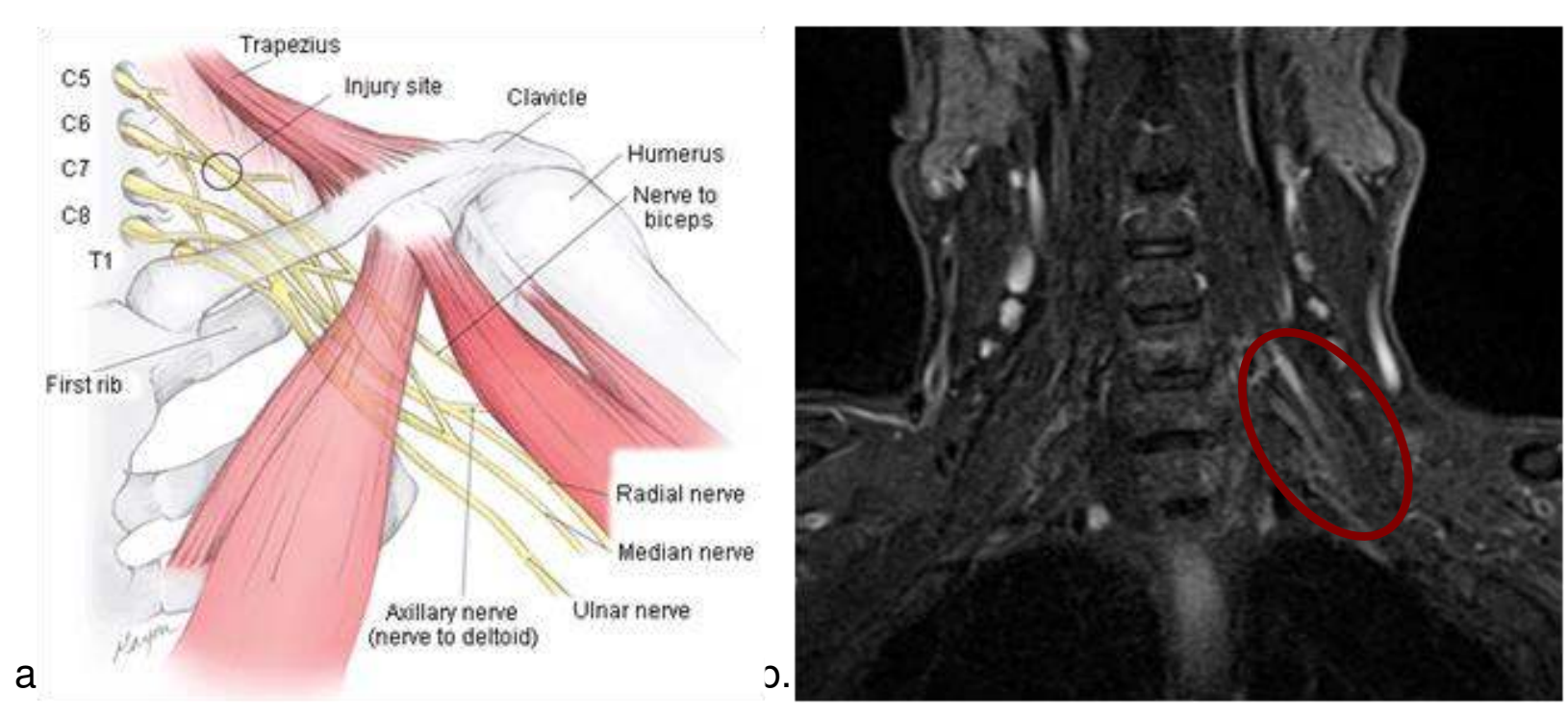

Figure 1 - Brachial plexus anatomy and axillary nerve origin (a) and correlation with patient's resonance imaging (b) - red circle line represents C5 hyperintensity

Clinical Case A 55 year old physically active male (recreational cyclist), with previously known shoulder tendinopathy, developed left omalgia and decreased range of motion (ROM) following a 60 $\mathrm{km}$ bicycle ride. The patient presented one month following the onset, showing deltoid amyotrophy and scapular muscle weakness (Figure 2a). Clinical evaluation and image exams excluded new bone or ligament lesions from the glenohumeral joint. MRI revealed left C5 root hyperintensity (Figure 1b) suggesting a radiculitis process and EMG confirmed nerve lesion.
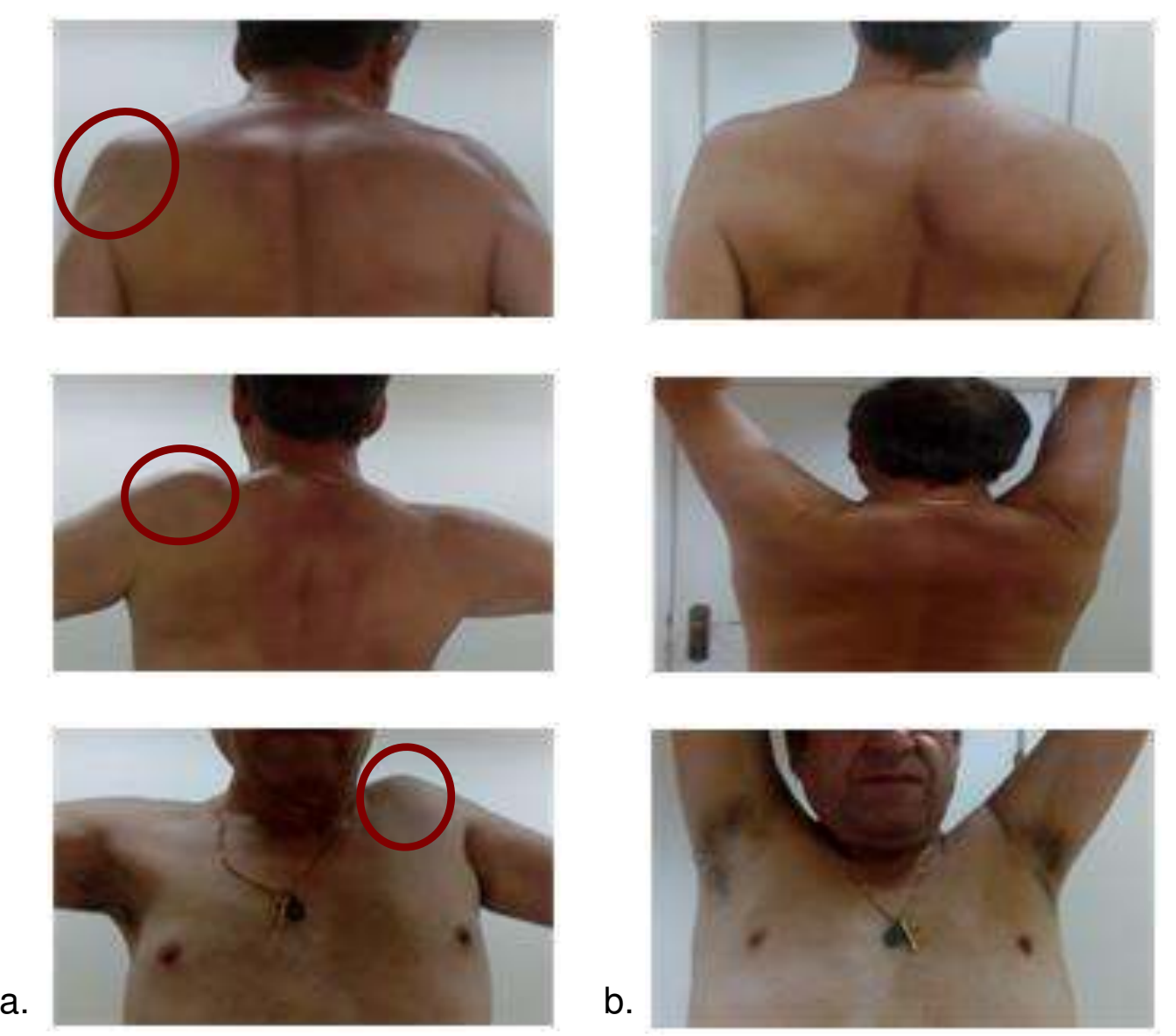

Figure 2 - Patient before the rehabilitation programme (a) and at re-evaluation appointment (b)
Results The patient underwent a rehabilitation programme including passive and active ROM exercises, stretching, local massage and TENS. At the re-evaluation appointment, approximately 4 months following the injury, the patient revealed major improvements (Figure $2 b$ ) by regaining deltoid muscle mass, muscular strength and ROM.

Discussion Shoulder pain and dysfunction are common causes for P\&RM referral and their management entails a broad range of differential diagnosis including rotator cuff tear, impingement, tendinitis, bursitis, adhesive capsulitis, radiculopathy, osteoarthritis, but also cardiac causes (e.g angina pectoris), vascular causes (e.g. thoracic outlet syndrome) and pulmonary causes (e.g. lung cancer). Despite being a relatively frequent cause for such symptoms, axillary nerve lesion remains underdiagnosed. In the majority of the cases, the injury is associated with blunt or penetrating trauma, which can initially dominate the physical exam and narrow the diagnostic possibilities, nonetheless it also occurs in the context of minimal or no trauma, mainly due to nerve compression (Table 1 ).

Table 1 - Axillary nerve injury causes and clinical management

\begin{tabular}{|c|c|c|}
\hline Causes & History and physical exam & Imaging exams \\
\hline $\begin{array}{l}\text { Parsonage - } \\
\text { Turner } \\
\text { Syndrome }\end{array}$ & $\begin{array}{l}\text { Pain followed by loss of motor function } \\
\text { and amyotrophy. Recent respiratory } \\
\text { infection may be associated }\end{array}$ & $\begin{array}{l}\text { Nerve hyperintensity on } \\
\text { MRI and decreased } \\
\text { conduction on EMG }\end{array}$ \\
\hline $\begin{array}{l}\text { Glenohumeral } \\
\text { dislocation or } \\
\text { fracture }\end{array}$ & $\begin{array}{l}\text { Injury due to traction and compression. } \\
\text { Previous episodes. Hyperlaxity of other } \\
\text { joints. Severe pain and reduced ROM }\end{array}$ & $\begin{array}{c}\text { Radiography (AP, axillary } \\
\text { lateral or scapular Y } \\
\text { view). MRI. }\end{array}$ \\
\hline $\begin{array}{c}\text { Nerve } \\
\text { compression }\end{array}$ & $\begin{array}{l}\text { Due to bone tumours, abnormal } \\
\text { fracture callus, axillary artery aneurysm. } \\
\text { Insidious and systemic symptoms }\end{array}$ & CT-scan and MRI \\
\hline $\begin{array}{l}\text { Quadrilateral } \\
\text { Space } \\
\text { Syndrome }\end{array}$ & $\begin{array}{l}\text { Dull pain and nondermatomal } \\
\text { paresthesia. Possible digital ischemia }\end{array}$ & $\begin{array}{l}\text { Arteriogram: artery } \\
\text { occlusion at } 60^{\circ} \\
\text { abduction }\end{array}$ \\
\hline
\end{tabular}

Conclusions Axillary nerve injury should be considered in the assessment of shoulder pain and dysfunction, even in the presence of previously known shoulder pathology. Clinical history and physical examination have a pivotal role and MRI and EMG are the diagnostic gold standards. Prompt diagnosis correlates with favourable outcome and the majority of patients have an excellent prognosis with nonoperative therapy.

\section{Bibliography:}

1. Mitchell JJ, Chen C, Liechti DJ, Heare A, Chahla J, Bravman JT. Axillary Nerve Palsy and Deltoid Muscle Atony. JBJS Rev. 2017;5(7):1.

2. Moser T, Lecours J, Michaud J, Bureau NJ, Guillin R, Cardinal É. The deltoid, a forgotten muscle of the shoulder. Skeletal Radiol. 2013;42(10):1361-1375.

3. Safran MR. Nerve Injury about the Shoulder in Athletes, Am J Sports Med. 2004;32(3):803-819

4. Steinmann SP, Moran EA. Axillary Nerve Injury: Diagnosis and Treatment. J Am Acad Orthop Surg. 2001;9:328-335. 